\title{
PRESENT AND FUTURE TRENDS OF GRASSLAND RESEARCH IN THE UNITED STATES
}

\section{Milton A. SpRague}

Rutgers University, New Brunswick, New Jersey, U.S.A.

WHEN your chairman asked for a description of grassland research in the United States, present and future, the mere thought of the task brought me a picture of a flea contemplating an elephant. Grassland agriculture is so large and varied in its entirety, is spread over so many disciplines, and is so complex in the interrelationships of the biological, social and economic communities that I can only hope to comment on how this flea views the rapidly changing giant.

Grassland agriculture is not new in the United States, although intensive research on grassland problems dates back only about four decades. No one more vigorously protected his range than did the American cowboy, yet in most instances he was fighting the wrong spoilers. Most of his heritage of thick prairie grass sods were lost to either the plough or poor grazing management. Today most Americans think of the range as a place to ride, getting their impression from television movies. A growing number, however, realize the great importance of our grasslands, both range and pasture, as crops that do much to serve our growing population better every day.

As each segment of grassland farming has progressed, the real problems have become apparent in increasingly more rapid succession. Each new finding inspires new opportunities to improve the contribution of grass to daily living.

By far the most important single research development in recent years is the extent to which sophisticated, problemoriented scientists- have co-ordinated their investigations as a team effort. Co-operative research by competent men in many disciplines has opened broad new horizons of opportunity previously closed to the individual working alone. And this includes co-operation with and within industry as well as public-supported institutions. The result has been that the role of the grassland farmer has changed from that of a labourer to a business manager. More than any other farming today, and in the future, the primary function of the farm and ranch operator will be to 
steer a many-faceted operation in the right direction at precisely the right time to turn a profit. The back work of lifting bales and pulling weeds has been transferred to electric power, chemicals and fossil 'fuels. In a society geared to progress, success is measured by timely competitive adjustments and changes guided and supported by pertinent problem-oriented research.

Some very interesting things are going on' in grassland, research which I believe will bring about exciting changes in the foreseeable future. One major effort is to better plan the research itself..

On order of the Senate of the United States, in 1965, there was undertaken an evaluation of agricultural research throughout the country. Based on this inventory,. a "National Program of Research for Agriculture" was prepared with recommendations for adjustments, priorities and allocations of resources for research during the next 10 to 15 years. Manpower needs and areas of needed emphasis were delineated on a national scale and a report made available in October, 1966. A -supplement to this study, dealing with "Forage Range and Pasture" (1968), was expanded by an in-depth long-range study into the specific present and future research needs for the nation's grasslands. In its manner of preparation, virtually every public service scientist in the country involved in research with the forages participated. Attempts were made to evaluate the forage situation as it exists, organize both problems and opportunities, identify centres of excellence, and recommended further -development of needed research. It was recognized that fragmented and isolated research is often inefficient and unrewarding. Integrated research programmes with special competence in the related disciplines were proposed for the solution of critical problems. This Forage and Range Task Force report indicates that protection and production research is distributed among 38 specific objectives with a recommended overall increase in research effort of $70 \%$ by 1977 . A national inventory of the extent and productivity of pasture and range is urged. Improvement in range management, to stem the depletion of this resource, emphasizes brush control, range reseeding, water yields, erosion,' and recreational opportunities. Research on weed control in all forages including both brush and noxious plants is recognized as a major problem in need of double the research effort by 1977. Research on insect and disease control is considered in need of both expansion and readjustment under what is termed protection. 
The recommendation for a grassland inventory is very timely. For the first time a national census of grasslands appears to be a real possibility. High-level remote sensing devices involving special cameras, -ultra-violet, visible, infra-red and micro-wave regions of the electronic spectrum, together with specially designed films and photographic reading devices have been developed largely by the National Aeronautics and Space Administration laboratories. With these new tools, an earth resources satellite is contemplated which will scan, identify, and evaluate the earth's surface. This constitutes looking back at ourselves from space as a means of self-analysis and has great meaning to our forests and grasslands.

To date flying aircraft have shown that crops can be' identified, diseases detected, insect infestations mapped, soil conditions observed, and crop relations revealed. Each "special signature" is coded to a computer for evaluation of chemical and physical properties based on known models.

Of particular merit will be successive measurements at appropriate time intervals to detect a progression of events.

The potential impact of information to be gained from such a survey of grasslands is tremendous. Manipulation of grazing pressures, fertilization. schedules, irrigation needs, and control of insect and disease epidemics will be possible as never before. The work of. perfecting techniques and data evaluation procedures is under way in three or four laboratories at present.

The long-range study further indicates that the major portion of current research is conducted under what is called "biological efficiency". Still, work -with a substantial number of forage species is inadequate. Adjustments in related technology have eroded the competitive position of many commonly used forages to where improvements in their performance have not kept pace with other field crops. Further, new varieties have greatly increased the importance of some crops for specific purposes in newly developed livestock enterprises.

Also, growth, dormancy, maturity and vegetative re-. generation patterns in forage plants have been considered since research with forages began. Unlike the grain crops, however, . forages rely directly on the meristematic vegetative regeneration of tissues for their survival. Bud and crown formation is the very essence of both yield and competition in perennial plants. Physiological studies have measured and reported many responses to cultural treatments and plant breeders have selected germ plasm with this in mind. However, the regulatory mechanisms within 
tissues and cells which control vegetative vigour, competition and maturity are not well known and the enzyme chemist and biophysicist are charged to search for a means of growth control,

How. and why do different plants respond vegetatively to daylength, temperature, moisture, light quality, mineral nutrition, defoliation,. maturity, stand density and competition? In one lucerne study (Cowett and Sprague, 1963), a multiple correlation representing eighteen such variables accounted for only $54 \%$ of the variation in number of buds 'produced; $46 \%$ was unaccounted for. Stand density exerts the most pronounced effect on number of stems .per plant. : However, since stand density also alters soil moisture, light quality, light intensity, soil temperature and plant temperature, the chain of influence, when one factor governs the value of another, creates a dynamic ecosystem of competition which taxes the imagination to evaluate.

Physiological control of maturity in forage plants in itself is a great challenge. 'To be able to delay- maturity. in lucerne sufficiently to maintain continual vegetative 'growth would have great value in forage production. Such capacity for growth control would permit flowering only when needed and increase vegetative production considerably. The answer likely lies in the internal chemical-energy system of the cell.

Fprage harvesting and preservation is a critical area much in need of interdiscipline research. Developments in handling and storage equipment have made considerable progress in reducing storage losses and labour costs. Better constructed silos have not only reduced total dry matter losses to less than $3 \%$ but 'operationally designed structures are doing other tasks. Self-feeding silos and barn systems with beef have reduced labour for a 50 cow herd to about 20 minutes per day. At least one experimental unit (at Rutgers University) is being tested with a 50-cow dairy herd Where the desired balanced ration, using urea as a protein source, is mixed as the silo is filled. Additional individual cow needs are met in the milking parlour.

Anaerobic storage at cool temperatures within a degree or two of the freezing point has experimentally preserved chopped succulent lucerne through a' 5-month storage period with no detectable physical or chemical changes (Sprague and Taylor, 1966). Dry ice pellets were employed for rapid cooling and the energy requirement of maintenance refrigeration was very small. The next logical step in this development, a freeze-dried forage of very high 
quality, is currently being explored in Kentucky and Wisconsin.

Another dynamic development in grassland agriculture is systems analysis. The varied nature of the soil-grasslivestock complex makes the opportunity for co-ordination of improvements in efficiency of forage and pasture production, storage and utilization essential. Systems studies must be conducted in several regions to apply the law of comparative advantage to alternative crops, equipment, and classes of livestock.

Already vertical integration in the livestock has expanded downward from the large feedlots to cow-calf herds and crop production and upwards to slaughter services and the processing of by-products. The rewards in efficiency which accrue from this type of professional management are most reassuring. Computers are extremely helpful in carrying out this type of analysis through their capacity to rapidly sort out and manipulate data descriptive of each crop, each animal, each tractor and each step in the entire operation.

Only a small segment of this type of control analysis is under way at present. The most widely used is probably that among the dairymen in regulating supplementary feeds in relation to forage quality and animal performance. The long-range study proposes that the research effort in systems analysis be expanded at least four times during the next 10 years.

Identification of quality in the market place has been a challenge for many years, Recently, animal studies to identify forage quality plus increased commercial traffic in processed forages, such as pellets, wafers, silages and mixed feeds used in specialty livestock operations, require more than an empirical evalution of feeds.

A uniform system of grading based on laboratory measurements of known constituents should be -instituted during the next decade. This will be necessary both for the market sale of these feeds and the management of integrated systems. Efficient feeders can no longer afford to guess at what they are feeding breeding stock, young stock or slaughter animals. Production schedules will demand a reliable knowledge of inputs to substantiate effective management decisions.

Consistent with direct marketing of. grassland feeds is the need to develop improved efficiency and flexibility in the marketing of livestock products. This may be accomplished through. the development of alternative marketing opportunities recognizing improvements in production 
efficiency and in particular identification" of quality aspects of the product as it relates to changing choices of the consumer.

The agronomist, animal scientist, and economist must not only remain alert to major opportunities based on the research findings in allied fields but also co-ordinate their experiments to "complement one another. Considerable improvement in rate of gain and quality of products is now possible through superior forages, blood-lines, balanced diets and timely hormone injections. This kind of "growth control" in animals results in double muscling, faster growth rates, higher calving percentages, and more better cuts of meat and improved composition of milk, to mention just a few.

Two exciting new developments in animal science which will have an impact on grassland farming include two lamb crops per year and multiple births in cattle. Making use of progesterone-like hormones to promote. out-of-season breeding, twice-a-year lambing is expected in time to permit a 300\% lamb crop in the sheep industry. Already some blood lines such as the Finnish Landrace are strongly inclined towards multiple births.- Now the new problems become adequate care and nutrition of ewes and young lambs, under a new system of early weaning.

An $85 \%$ calf crop is average in most good beef herds, which places the calf as the most costly item in producing a beef carcass. Now a large proportion of available grasslands are required to maintain the cow. Hormone treatments have raised this calving percentage to an average of 1.11 weaned calves per cow in herd experiments at Reno, Oklahoma, and promise to do much better. Multiple births have been recorded as high as quintuplets but twins and triplets are more frequent and much to be desired. The major benefit is reduction in the number of cows required to maintain a supply of calves for feedlot operations.

It appears to me that such a development will require major adjustments in cow and calf management as well as forage crop management. First, a special beef cow will-be needed, perhaps a Holstein cross, to increase milk pro-: duction for a nursing period of perhaps two months on heavy feeding on high quality grass.

The calves, following early weaning, will need high quality forages and supplements to maintain a $2 \frac{1}{2}$ to $3 \frac{1}{9} \mathrm{lb}$ per day gain all the way through to finishing in the feedlot. Marketing a 1,OOO-1,100 lb animal could conceivably be at 1.2 months of age. Rebreeding of the cows would be to outstanding bulls by artificial insemination, while in partial 
confinement with the calf, after which they would be ranged on an abundance of average quality forage throughout gestation.

Such a sequence would have the obvious advantages of fast growth and associated efficiency plus a higher quality carcass; full use of high quality forage where it would have its greatest effect; utilization of mediocre quality forage (of which every farm has some) and in particular close management control of the entire crop-livestock operation with opportunities for vertical integration.

Injections of folicle-stimulating and ovulating hormones in proper succession are delicate operations, however, which are sure to have' influence on the health and subsequent performance of females. Much research will be needed before dependable procedures can be perfected.

'Another area due for expansion of research effort is the processing and marketing of forage products apart from direct feeding. to livestock. One of the most exciting is that of leaf protein obtained by juice extraction from fresh-cut young lucerne. Other forages including the annual grasses also should be explored for this use.' Protein production per land unit is about double that from the best of the seed crops, such as soybeans and cereals, and the proteins obtained have a good balance of essential 'amino acids greatly in demand for human food as well as for special livestock situations.

Only a portion of the proteins are removed by passing green lucerne through rollers to press out the nearly fibrefree cell juices. These leaf proteins are high in lycine and methianine so essential for fast growth of simple stomach mammals" When dried, the extract tests $35 \%$ protein and only $0.7 \%$ fibre. The crop residue still tests about $16 \%$ protein after extraction and at a lower moisture content can be easily fed or ensiled for ruminants. Developments such as tbis hold great promise to help meet food problems in diet-deficient regions of the world (Stahman, 1968).

My appraisal of current and new research with the nation's grasslands would not be complete without mention of an old problem now gaining new perspective. as urban populations increase. Environmental pollution is a nice word for inadequate waste disposal. Concentrations of 50,090 cattle in feedlots produce, mountains of manure which can and do pollute aquafers. Concentrations of large numbers of poultry or hogs near suburban communities pollute the air to a point where the customers themselves do not find living pleasant. What once was called "country atmosphere" is no ionger acceptable. Excessive nitrates 
in ground waters, streams, and ponds, contribute to aquatic weed -problems and unpleasant recreation areas. $R$ e distribution of waste products is currently being largely ignored as an integral, part of production management in many livestock industries. As population pressures (including urban wastes) increase, our policy slogan can no longer be "The solution to pollution is dilution." We must -find ways to recycle these by-products'to reuse them. Nitrogen products constitute our greatest single group of pollutants and grasslands will assuredly play an increasing role in recycling the nitrates, at the same time maintaining the world's supply of protein Grasses are our best scrubbers 'of the environment to cleanse. it of such unwanted wastes.

In summary: Several developments in grassland farming appear to me to be assured by the year 2000. The predicted increase in population in the United States alone will demand more quality meat and other livestock. products in support of better living. Livestock numbers are expected to double and improved production efficiency must continue with grass to lower the real cost to the consumer. Grasslands will contribute much to this growth but research must find ways to improve their production efficiency and processing to better serve. mankind.

Ways will be developed to take inventory of the grasslands in order that this great natural resource can be identified, evaluated, improved and managed. New systems will evolve using sophisticated computers for analysis of each input for its contribution to the whole operation. Professional management teams will become commonplace and their influence will be felt on larger acreages and in larger operations.

It appears to me that new crops must be sought for, better controlled environments and biological control of the growth of both forage crops and livestock. Greater production efficiency will improve the quality of forages and lower their cost to remain competitive with other feeds. Maturity and vegetative regeneration of forages will. be brought more effectively under control. The nature of competition between plants will be studied as the science of biophysics opens an understanding of the energy relationships of cell chemistry and permit regulation of growth itself.

Hybridization in livestock production will likely be extended as well as multiple births and greatly improved feeding techniques with new forages. 'Hay and silage will remain the primary form of forage preservation but some high quality forages will also be freeze-dried. Further, 
great research effort will be put to recycling the evermounting waste products and this cost must be borne both by the consumer who demands a cleaner environment in which to live and the farmer who will find it necessary to stay in business. Grasslands with their capacity as scrubbers of the air, soil and water will play a dominant role.

All of these developments in present and future research lead me to recognize that grasslands serve the world in many ways: to beautify the landscape, provide for social and recreational needs, and, through the efficiency of more and better forages, to provide higher quality livestock products to sustain a growing population.

\section{REFERENCES}

National Program of Research for Agriculture: Joint report of association of State Universities and Land Grant Colleges and U.S. Department of Agriculture, Washington, D.C. October, 1966.

$N$ ational Program Of Research for Forage, Range and Pasture: Prepared by a Joint Task Force of the U.S. Department of Agriculture and the State Universities and Land Grant Colleges, Washington, D.C. November, 1968.

Cowett, Everett R.; Sprague, Milton A., 1963: Effect of stand density and light intensity on the micro-environment and stem production in alfalfa. Agron. J., 55: 432-4.

Sprague, Milton A.; Taylor, B. Brooks, 1966: Preservation of green chopped alfalfa at near freezing temperatures. Ibid. Agron. J., 58: $179-81$.

Stahman, M. A., 1968: The potential for protein production from green plants. Econ. Bot., 22: 73-9.

\section{DISCUSSION}

Langer sought information on the method used to evaluate priorities in research and suggested that it might be easier in a large rather than in a small country. Sprague said that evaluation was a monumental task which involved going to industry and to all spheres of research. Eventually a consensus of opinion was represented but it was complicated by the vastness of the task. He did not think it could be more easily carried out in a large country; in fact, there would be more opportunities for closer understanding in small countries.

O'Connor asked for comment on a figure quoted by a recent visitor from Wisconsin that for every kcal of food placed on an American table more than $1 \mathrm{kcal}$ of fossil-fuel was used to put it there. Was the cost of production- in social costs being considered? Sprague replied that fossil-fuels were considered, but he did not know the exact extent. It was -difficult to identify how the kcal was used. 
Marten (U.S.A.) commented that they had heard from New Zealanders that pasture was the cheapest source of feed, as indeed was it quoted in their classical textbooks. With their feedlot system with all-the-year-round confinement, would it still be the cheapest food in 15 or 50 years' time?

Sprague thought that every enterprise was a separate economic situation. One hundred lb TDN cost $\$ 1.70$ as pasture, $\$ 3.00$ as silage or hay, or $\$ 6.50$ as grain crops, so pasture was a very efficient producer. It had to be considered whether it was cost of production, return per dollar, or per acre, or per man, and what was the limiting factor-dollar to be invested, livestock, labour, or land? 